\title{
Ensino técnico na área da saúde: os desafios do processo de aprendizagem.
}

\section{Formação profissional e o ambiente de aprendizagem}

\author{
Beatriz Lemos Stutz \\ Adriane Corrêa Jansen
}

\section{Resumo}

O presente estudo teve como principal objetivo investigar quais são as dificuldades encontradas por alunos de um curso técnico de nível médio, na área de enfermagem, frente às atividades realizadas no estágio curricular. Participaram do estudo os alunos do $2^{\circ}$ período do referido curso, através do registro de suas dificuldades mais significativas em uma ficha de atividades diárias, por um período de cinco dias úteis. Os resultados revelaram que as maiores dificuldades referiam-se a relacionamento interpessoal e comunicação.

Palavras-chave: Psicologia escolar; Aprendizagem; Educação profissional.

\section{Technician education in health area: the challenges of the learning process}

\begin{abstract}
The present study aimed to investigate which are the difficulties of the students in a nursing technical course during activities of curricular practical training. Second degree students had participated of the study period by reporting in a special form there most significant difficulties during daily activities for a period of five days. The results showed that the relationship and communnication were the most important difficulties.

Keywords: Educational psychology; Learning; Professional education

\section{Enseñanza técnica en el área de la salud: los desafíos del proceso de aprendizaje}

\section{Resumen}

Este estudio tuvo como objetivo principal investigar cuales son las dificultades encontradas por alumnos de un curso técnico de nivel medio, en el área de enfermería, frente a las actividades realizadas en las prácticas curriculares. Participaron del estudio los alumnos del $2^{\circ}$ período del referido curso, através del registro de sus dificultades más significativas en una ficha de actividades diarias, por un período de cinco días útiles. Las mayores dificultades foran relación entre enfermería y comunicación.

Palabras-clave: Psicología escolar; Aprendizaje; Educación profesional. 


\section{Introdução}

Compreender os desafios inerentes ao mundo do trabalho, afetado por inúmeras e rápidas transformações que caracterizaram o século $X X$ e continuam, na atualidade, em um processo cada vez mais acelerado, redunda em uma complexa tarefa, cujas implicações atingem diretamente a produção acadêmica, uma vez que esta se insere na elaboração de conhecimentos sistematizados sobre o mundo em que vivemos.

Ao abordar a profissionalização e a educação na área de saúde, Stutz (1999) ressalta que o processo de globalização e o vertiginoso ritmo dos avanços científicos e tecnológicos têm exigido do homem um esforço cada vez maior no sentido de assimilar, incorporar e adaptar-se às mudanças crescentes. Tal realidade impõe enormes desafios ocupando a qualificação profissional e a formação em serviço, lugar de destaque no mercado de trabalho.

Historicamente, as mudanças ocorridas no mundo do trabalho exerceram influência direta na educação marcando as trajetórias das políticas públicas educacionais pertinentes ao ensino profissional. Nesse sentido, Oliveira (2000) destaca o Decreto 2208/97, referente à Reforma do Ensino Técnico e à resistência das instituições para sua implantação uma vez que os processos escolares formativos da educação profissional têm se aproximado dos métodos de treinamento do trabalhador, prevalecendo uma formação meramente técnica.

$\mathrm{Na}$ sociedade atual, novas exigências, para além do domínio de técnicas e simples realização de tarefas, requerem do setor educacional esforços no sentido de contribuir para uma ampla formação do indivíduo. Dessa forma, as mudanças vivenciadas pela sociedade no mercado de trabalho passam a solicitar nova postura do ensino técnico em que as transformações tecnológicas, consideravelmente mais rápidas, passam a ter por base a capacidade de cooperação e trabalho em equipe (Maluf, 1998).

Ao analisar a educação profissional, Ramos (2002) se refere às reformulações teóricas e socioempírica cujas tendências incidem mais fortemente sobre a política educacional nessa área, a partir dos anos 90 .
Segundo essa autora, as reformas educacionais associaram-se aos processos de globalização da economia e à crise de emprego aproximando a educação das tendências produtivas. $O$ conceito de qualificação, aliado à noção de competência, incide diretamente sobre os parâmetros de formação profissional, cuja legislação passa, a partir da separação entre ensino médio e técnico, a introduzi-la como referência essencial.

Lopes (2002) enfatiza que os Parâmetros Curriculares Nacionais para o Ensino Médio se expressam não apenas pela listagem de competências e habilidades mas também por uma estreita associação entre educação e mundo produtivo. Os Referenciais Curriculares Nacionais da Educação (Brasil, 2000) originados de estudos realizados pela Secretaria de Educação Profissional e Tecnológica do Ministério da Educação, no que diz respeito à área de saúde, traz uma matriz curricular referencial para os cursos existentes, com clara alusão a uma formação que estimule a autonomia, exercício das funções mentais, cognitivas e socioafetivas, assim como a assimilação de novos conhecimentos, flexibilidade e criatividade. Há ainda uma clara alusão ao papel do profissional da saúde enquanto educador e sua importância na busca de alternativas para diversos problemas enfrentados nessa área.

Em outra vertente, Laudares e Tomasi (2003) questionam a essência dos discursos presentes no mundo do trabalho e no meio acadêmico ao veicularem que as inovações tecnológicas e organizacionais transformaram o primeiro, demandando um novo trabalhador. Tais autores evidenciam que talvez não seja preciso um novo trabalhador, mas sim reconhecer nele qualidades não percebidas até então.

Uma avaliação sobre tais discursos também é feita por Silva (200I), apontando a contradição entre esses e a realidade vivenciada, tanto no interior das empresas quanto no das escolas, que acabam por cercear os trabalhos criativos, autônomos e cooperativos.

Diante do exposto, percebe-se que a educação profissional enfrenta na contemporaneidade, mais do que nunca, grandes desafios com implicações diretas na prática docente e no trabalho educativo em geral. 
As transformações políticas, econômicas e sociais que permeiam a atividade laboral e, por conseguinte, a legislação pertinente à educação, confirma a influência de cada época nos conteúdos e nas práticas pedagógicas que caracterizam o ensino e o processo de formação no interior das instituições.

Para Ramos-de-Oliveira (200I), a educação pressupõe comunicação real e troca de informações entre as pessoas, que enriquece, transforma e contribui para a formação do outro, provocando uma reorganização do todo. Fagundes \& Burnham (2005) ressaltam a importância da reflexão sobre as aprendizagens da prática, devendo ser objeto de preocupação e estudo, para que se possam subsidiar mudanças significativas no processo de formação, contribuindo para a construção de eixos curriculares e uma atuação docente que possibilite o desenvolvimento de cidadãos socialmente responsáveis e com capacidade de reflexão sobre seu trabalho.

As experiências em instituições públicas representam uma parcela significativa dos processos de formação no país. Baseado nisso, ao tomar-se como objeto de estudo as implicações das ações desenvolvidas durante o estágio curricular junto a alunos de um curso técnico de nível médio, na área saúde, busca-se recuperar e registrar aspectos importantes de seu processo de formação, desvelando um cotidiano sobre o qual, nas palavras de Pezzato (200I), pouco se tem publicado a respeito.

Nesse contexto, torna-se necessário, segundo Martins (2003), criar condições para que o aluno possa ser ouvido e compreendido ao falar de seus sentimentos em relação a si mesmo e ao cliente, assim como perceber seus erros e acertos, uma vez que esses últimos tornar-se-ão fundamentais na construção de sua identidade profissional.

Ao abordarem as dificuldades a partir da visão de alunos de nível técnico em enfermagem, Kobayashi \& Leite (2003) ressaltam a busca desse profissional por espaço na área de saúde, enfatizando que para isto torna-se necessário o desenvolvimento de competências político-institucionais, ético-legais e técnicas.

Diante do exposto, por representarem as experiências em instituições públicas uma parcela significativa desses processos de formação, as autoras deste artigo, ao atuarem como docentes em uma escola federal do ensino técnico de nível médio, na área de saúde, cuja realidade elas têm vivido e acompanhado ao longo dos últimos anos, procuraram realizar uma reflexão mais aprofundada sobre esse universo a partir da sistematização de dados provenientes de uma atividade realizada em sala de aula, tendo como tema as experiências vivenciadas pelos alunos no estágio curricular, esperando dessa forma poderem contribuir para a ampliação e a disseminação de novos saberes relativos à educação profissional. Buscou-se, portanto, analisar quais as implicações das atividades desenvolvidas pelos alunos durante o estágio curricular em seu processo de formação profissional e em que medida as experiências vivenciadas por eles, no contato com a comunidade e na realização de atividades práticas, podem oferecer subsídios para a elaboração de referenciais didáticopedagógicos que atendam às necessidades percebidas.

\section{Método}

\section{Participantes}

Participaram do estudo 32 alunos do $2^{\circ}$ período de um curso técnico em enfermagem de uma escola pública federal de ensino técnico de nível médio, na área de saúde, que estavam realizando atividades de estágio curricular em unidades de atendimento em saúde com acompanhamento docente.

\section{Instrumento}

Como instrumento de coleta de dados, utilizou-se uma Ficha de Atividades Diárias, apresentada a seguir. A mesma é uma adaptação de exercícios propostos por Knapp \& cols. (2002), enquanto recursos da Terapia Cognitivo-Comportamental, constando de uma "Lista de Problemas" e "Como Solucionar um Problema", publicadas por esses autores, originalmente como exercícios distintos. $\mathrm{Na}$ presente pesquisa, os exercícios foram adaptados e incluídos lado a lado como tarefa única. 


\section{FICHA DE ATIVIDADES DIÁRIAS}

\section{LISTA DE PROBLEMAS COMO SOLUCIONAR UM PROBLEMA}

\begin{tabular}{|l|l|}
\hline Segunda-feira & 1- Escolher um problema da lista \\
\hline Terça-feira & 2- Possíveis soluções para o problema \\
\hline Quarta-feira & 3-Conseqüências das soluções encontradas \\
\hline Quinta-feira & 4-Escolha de uma solução encontrada \\
\hline Sexta-feira & 5-Sentimento conseqüente a essa escolha \\
\hline
\end{tabular}

Fonte: Knapp, P. e cols. (2002). Terapia Cognitivo-comportamental no Transtorno de Déficit de Atenção/Hiperatividade: manual do paciente. Porto Alegre: Artmed, pp 35 e 71 . Adaptado com autorização.

\section{Procedimento}

O instrumento de pesquisa foi preenchido individualmente pelos participantes, por um período de cinco dias úteis consecutivos, abrangendo os dias semanais (segundas e quartas-feiras) em que é realizado o estágio curricular nas unidades de saúde.

Cada participante foi orientado a preencher primeiramente os itens da Coluna I (Lista de Problemas) e, somente após o último dia de registro, a Coluna 2 (Como Solucionar um Problema) deveria ser preenchida, conforme a seqüência de itens existentes. A apresentação dos dados foi autorizada mediante a assinatura do Termo de Consentimento Livre e Esclarecido. Para assegurar o sigilo quanto à identidade dos participantes, as fichas foram numeradas de I a 32.

Vale ressaltar que a aplicação desse instrumento de pesquisa teve sua origem quando da constatação por uma das autoras, enquanto docente da turma em questão, quanto à necessidade de se trabalharem os conteúdos propostos na grade curricular, utilizando recursos didáticos que propiciassem aos alunos a troca de experiências em sala de aula, acerca dos caminhos que envolvem $\circ$ processo de aprendizagem e a formação profissional, incluindo o estágio curricular, não se restringindo a uma prática pedagógica tradicional, caracterizada pela exposição de conteúdos pelo professor, visando a contribuir, portanto, para uma participação ativa dos discentes em seu processo de aprendizagem, possibilitando o desenvolvimento contínuo de habilidades humanas, enquanto trabalhadores da área da saúde (Pereira, 2003).

\section{Resultados e Discussão}

Em termos metodológicos, optou-se pela abordagem qualitativa com base no referencial da análise do discurso estabelecido por Bardin (1995), tendo sido elencadas categorias, a partir das respostas obtidas mediante o preenchimento da ficha de atividades diárias acima citadas. $\mathrm{O}$ conteúdo das fichas foi transcrito na íntegra e posteriormente selecionado, organizado e analisado considerando o relacionamento interpessoal, o medo, a motivação e o saber-fazer como categorias.

Na seleção e organização do conteúdo, não foram considerados problemas cuja origem não estivesse relacionada a situações de ensino-aprendizagem, tais como conflitos pessoais, familiares e do cotidiano de modo geral. O presente estudo tornou possível a reflexão e a elaboração de um conhecimento sobre aspectos que envolvem a formação de profissionais técnicos de nível médio, na área da saúde, durante atividades práticas supervisionadas.

Constatou-se, a partir da análise dos conteúdos, as dificuldades e a forte influência das relações interpessoais vivenciadas pelos alunos durante as atividades no local de trabalho, envolvendo os docentes, usuários dos serviços de saúde e equipe de profissionais. Verificou-se prevalência de um maior 
número de citações, pelos participantes, de problemas que envolvem funcionários durante as atividades de estágio, podendo ser observado na Tabela I.
Pode-se observar na Tabela I diferença entre as freqüências dos itens Dificuldades na comunicação e relacionamento com pacientes e Dificuldades no

Tabela I. Problemas mais freqüentes apontados pelos alunos, durante as atividades de estágio curricular

\begin{tabular}{lc}
\hline \multicolumn{1}{c}{ Problemas } & Freqüência \\
\hline Acidentes & 1 \\
Conflito entre a técnica aprendida e a técnica praticada & 4 \\
Dificuldades em improvisar & 1 \\
Dificuldades em lidar com o sofrimento de pacientes e a morte & 4 \\
Dificuldades em realizar tarefas sob observação de terceiros & 2 \\
Dificuldades na comunicação e relacionamento com pacientes & 6 \\
Dificuldades no relacionamento com funcionários & 22 \\
Dificuldades ocasionadas pela falta de experiência ou conhecimento em determinadas situações & 6 \\
Falta de motivação para ir ao estágio & 3 \\
Falta de oportunidade em realizar a maioria dos procedimentos em enfermagem & 2 \\
Insegurança ao realizar as ações em enfermagem & 1 \\
Medo de não conseguir fazer medicações & 1 \\
Medo de agulhas & 1 \\
Medo de errar & 1 \\
Medo de fazer punção & 1 \\
Medo do inesperado & 2 \\
Sobrecarga de atividades & 2 \\
\hline
\end{tabular}

Dentre os problemas mais freqüentes com funcionários, subscrevem-se àqueles referentes aos processos de comunicação e relacionamento interpessoal (Tabela 2).

A presente pesquisa corrobora a afirmação de Kobayashi e Leite (2002), na qual a maior dificuldade apontada por alunos de nível técnico na área de enfermagem refere-se ao relacionamento e à comunicação, evidenciando a relevância desses itens para o exercício profissional. Contudo, diferentemente dessas autoras, que distribuem tais dificuldades de forma equânime entre equipe, enfermeiros, professores e pacientes, os dados aqui apresentados apontam uma dificuldade acentuada dos alunos no início do processo do aprendizado prático da profissão, com os funcionários junto aos quais atuam diretamente no cotidiano hospitalar, durante a realização dos cuidados. relacionamento com funcionários. Observa-se também, neste quadro, que o item Dificuldades ocasionadas pela falta de experiência ou conhecimento em determinadas situações inclui-se entre os problemas mais freqüentes enumerados pelos alunos. Ao fazer-se uma análise dos níveis de freqüência em relação aos problemas registrados na Tabela I, constata-se que as ações específicas da área de enfermagem, ligadas aos procedimentos técnicos e de cuidados, colocam as dificuldades ocasionadas pela falta de experiência ou conhecimento em determinadas situações no mesmo nível de freqüência das dificuldades de comunicação e relacionamento com pacientes. Nota-se ainda que os itens referentes à categoria Medo, mesmo que ocasionados por determinado objeto ou situações específicas, somam, em seu conjunto, a mesma freqüência que os itens citados anteriormente 
Tabela 2. Problemas mais freqüentes com funcionários apontados pelos alunos durante as atividades de estágio curricular

\begin{tabular}{lc}
\hline \multicolumn{1}{c}{ Problemas } & Freqüência \\
\hline Dificuldade em lidar com contradições de funcionários que, em alguns momentos, & 1 \\
mandam fazer algo e logo em seguida dizem que aquilo não era para ser feito & 1 \\
Lidar com "implicâncias" de alguns funcionários em relação aos estagiários & 1 \\
Resistência de alguns funcionários em acompanhar os alunos com receio & 1 \\
de atrasar suas atividades diárias & 2 \\
Sentimento de ser explorado pelo funcionário & 4 \\
Indiferença por parte de alguns funcionários & 2 \\
Dificuldade em lidar com a instabilidade de humor e ofensas por parte de alguns funcionários & 4 \\
Recusa de funcionário a ficar com estagiário de plantão & 1 \\
Resistência de funcionário a orientar professores e alunos & 1 \\
Funcionários consideram os estagiários “preguiçosos" & 1 \\
Desconforto e insegurança frente aos funcionários & 1 \\
Funcionário relapso & 1 \\
Impaciência de funcionários com estagiários & 1 \\
Dificuldade em lidar com os erros dos funcionários & 1 \\
Dificuldade em lidar com funcionários & 1 \\
\hline
\end{tabular}

(comunicação e relacionamento com pacientes e falta de experiência ou conhecimento em determinadas situações).

No que se refere especificamente aos problemas relacionados às dificuldades no relacionamento com funcionários, apresentados na Tabela 2 , verifica-se que a instabilidade de humor e resistência dos funcionários a orientar professores e alunos são itens que apresentam maior freqüência nessa categoria, seguidos pela indiferença por parte de alguns funcionários e recusa a ficar com estagiário de plantão. A compreensão dos significados dos conteúdos registrados pelos alunos possibilitou a evidência de quatro categorias de análise.

\section{Categoria I - Relacionamento interpessoal}

Para Martins (2003), o aprendizado de novos papéis, como o de cuidador, que caracteriza a enfermagem, requer um ambiente de aprendizagem capaz de conter o excesso de ansiedade que 0 aluno enfrenta ao ter que lidar com as variáveis que permeiam o aprendizado, principalmente ao entrar em contato com os pacientes. Quando isso ocorre, contribui para a compreensão, elaboração e integração das situações difíceis. Dessa forma, uma atmosfera aberta e facilitadora atenua o estresse relacionado ao processo de profissionalização em oposição a um ambiente educacional intimidador.

Tendo em vista tais considerações, percebe-se, a partir desse estudo, que o processo de aprendizagem vivenciado pelo aluno do curso técnico em enfermagem é de tal modo influenciado pelo relacionamento com os profissionais da área, pacientes e seus familiares e professores, que se encontra na raiz da maioria dos problemas apresentados por eles, gerando grande desconforto e conflitos com os quais têm de lidar cotidianamente. Nota-se ainda que, ao analisar as expressões verbais dos discentes, não há preparo e interesse de fato das equipes de trabalho, no interior da instituição de saúde, para contribuírem de forma efetiva na formação do aluno, de modo a diminuir os impactos sofridos pelos aprendizes, ao depararem-se com a complexidade que permeia o processo do cuidar. Os discursos a seguir evidenciam o exposto:

"É um problema para eu saber que existem pessoas que não gostam de ensinar, ajudar os estagiários, 
pois estes foram estagiários um dia... e se demoramos para fazer alguma coisa, eles não deixam fazer mais nada. Fico revoltada e triste com estas pessoas." (Ficha 18)

"Tem profissionais no hospital que não gostam e não têm paciência com estagiários”. (Ficha 20)

“... ele é um funcionário experiente e essa experiência me ajudaria muito, até mesmo para o que eu não devo fazer quando eu for orientar um estagiário". (Ficha 3I)

A sensação de isolamento também é uma realidade vivenciada pelos alunos, causada pela indiferença de alguns funcionários:

"Sentimento de indiferença dos profissionais do setor onde eu estava. Tentava me enturmar mas me sentia isolada." (Ficha24)

Percebe-se que a forma apontada pelo aluno para solucionar esse problema tem como base a maior aceitação da equipe, cujo entrosamento ocasionaria um sentimento de bem-estar:

"Poderia tentar conversar mais com os profissionais e investigar o porquê daquela distância... a minha integração à equipe teria como conseqüência o sentimento de intimidade e de um ambiente agradável”. (Ficha 24)

Ao analisarem-se os registros obtidos, há ainda evidências de que manifestações de aceitação e cooperação por parte dos funcionários para com os estagiários contribuem diretamente para a diminuição da ansiedade e desenvolvimento da autoconfiança:

"Não fui muito bem aceita pela técnica que eu ia ficar, pois ficou achando que me acompanhar em algumas técnicas iria atrasá-la em seu trabalho... Solução: Mostrar para ela através do meu empenho e ajuda que eu não atrapalharia e conversar com a professora... Após algum tempinho ela já estava me tratando super bem e eu me senti mais segura." (Ficha 30 )
Os aspectos abordados nessa categoria não deixam dúvidas sobre quão importante é trabalhar as relações interpessoais no cotidiano hospitalar. Isso, porém, demanda a priori a elucidação dos fatores que contribuem para o surgimento dos problemas aqui apresentados, caso contrário, negar-se-ia o complexo universo que permeia o processo de humanização na saúde. Tais fatores têm sido apontados por diversos autores, a exemplo de Backes \& cols (2006), que chamam atenção para a necessidade de reconhecerem-se as dificuldades pelas quais passam muitas instituições de saúde no país, a exemplos dos cortes de verbas públicas, quadro profissional limitado, insalubridade, avanços tecnológicos e deficiência de recursos materiais, entre outros, gerando insegurança e insatisfação no trabalho, o que por sua vez contribui diretamente para relações de desrespeito entre os próprios funcionários.

\section{Categoria 2- Medo}

Medo e ansiedade são sensações freqüentemente presentes no cotidiano da enfermagem. Embora haja diferenças conceituais entre ambos, torna-se difícil separá-los uma vez que podem acarretar desconforto físico e mental.

Para Kaplan e cols. (1997), ansiedade e medo são sinais de alerta, distintos enquanto respostas a ameaças características. Enquanto a ansiedade é caracterizada como resposta a uma ameaça desconhecida, o medo inscreve-se enquanto resposta a uma ameaça conhecida, externa e definida. Para esses autores, a principal diferença entre ambos está na natureza aguda deste último e no caráter crônico do primeiro. Ainda para esses autores, quando considerados apenas como sinais de alerta, ansiedade e medo podem ser caracterizados como emoções similares.

Para Renon e Saad-Neto (200I), a origem do medo está relacionada à mudança de ambiente e à dúvida ocasionada pela dificuldade de um indivíduo em saber como agir em determinadas situações, acrescida de estímulos exteriores, acarretando o atraso na execução de atividades. Dessa forma, podese compreender que a categoria Medo esteja relacionada ao início das atividades do estágio 
curricular, por ocorrerem em um ambiente novo com o qual os alunos não sabem ainda como lidar.

Situações imprevisíveis levam ao medo do inesperado cuja forma de enfrentamento é apresentada no discurso a seguir:

"São vários os problemas que enfrentamos, mas o que mais é visível é o medo do inesperado que traz consigo a insegurança, pois o que é muito comum em um hospital é a mudança repentina no estado do paciente. E como saber qual será a nossa atitude diante de uma situação repentina como esta?... a única solução para essas e outras situações semelhantes é me tornar mais confiante, mesmo que pareça difícil enfrentar algum problema como esse. Devo acreditar que com o aprendizado, observação e treinos constantes, estaremos preparados para enfrentar qualquer situação". (Ficha I5)

A expectativa de poder estar em contato com os funcionários e aos poucos se adaptar às situações de aprendizagem no local de trabalho, possibilita a visualização da superação do medo:

“... por ter pouco tempo no setor e por ainda não conhecer a equipe, estou um pouco com medo, pois ouvi falar que tem pessoas no setor que não gostam de ajudar. $O$ melhor que tenho a fazer é esperar a minha adaptação e esperar que aos poucos eu consiga ter conversado com todos. Me sentirei muito mais à vontade". (Ficha 18)

\section{Categoria 3 - Motivação}

Aspectos intrínsecos ao ambiente de aprendizagem, aos processos de comunicação e relações interpessoais influenciam diretamente na motivação para ao trabalho. Para Davis e Newstron (2004b), a motivação é produto do ambiente cultural no qual o indivíduo vive, afetando o modo pelo qual percebe seu trabalho e encara sua vida. Assim, as pessoas têm diferentes interesses e diferentes forças motivacionais que afetam seu desempenho no trabalho. Dessa forma, a despeito dos recursos tecnológicos e equipamentos disponíveis no local de trabalho, é necessário que as pessoas estejam motivadas para utilizá-los. A motivação, portanto, é essencial para o envolvimento e ação do indivíduo.

Para esses autores ainda, manifestações de zelo, estima, confiança e valorização no trabalho ocasionam impactos positivos na saúde psicológica e física do trabalhador, assim como, satisfação e melhor desempenho. (Davis \& Newstron, 2004a)

O cansaço ocasionado pela carga horária destinada ao estágio e estudos em sala de aula, assim como desarmonia no ambiente de aprendizagem e inseguranças são apontadas no estudo aqui realizado como fatores desestimulantes para o aluno:

"Cansaço frente a jornada de estudos e estágio de 12 horas por dia". (Ficha 2I)

Vale ressaltar que a carga horária acima citada pelo aluno ocorre esporadicamente, quando há necessidade de realizar o estágio supervisionado no período da manhã e as aulas práticas no período da tarde. Estas últimas são realizadas regularmente nos mesmos dias da semana.

"Indecisão, ansiedade, desânimo em ir ao estágio devido à sensação de desarmonia no dia anterior. Baixa auto-estima, sentimento de insegurança e incapacidade". (Ficha 25)

"Hoje me deu uma enorme vontade de não ir pro hospital, por causa de minha insegurança”. (Ficha 27)

Os impactos das experiências relatadas pelos alunos sobre sua motivação podem em parte ser explicados por Martins (2003), ao dizer que grupos jovens geralmente são depositários tanto das esperanças quanto das partes fragmentadas das instituições, constituindo-se ao mesmo tempo ambiente propício para $\circ$ trânsito de suas fraquezas e aspectos não resolvidos. Essa dualidade, em muitos casos, impede a flexibilidade quanto às posições individuais e à criatividade, gerando papéis cristalizados. $O$ cuidado com a dimensão grupal é fundamental para o fortalecimento dos indivíduos, uma vez que a colaboração e a compreensão fortalecem os vínculos existentes, gerando diminuição do estresse. 


\section{Categoria 4 - Saber-fazer}

A presença do professor como suporte para o aluno durante a realização das atividades do estágio curricular é importante requisito no processo de aprendizagem. Além disso, a observação do aluno pelo professor possibilita um conhecimento das dificuldades apresentadas pelos mesmos, permitindo, segundo Kobayashi e Leite (2002), o planejamento de estratégias de auxílio a eles e acompanhamento de sua evolução.

Ao refletirem sobre a relação professora-aluna nas primeiras experiências práticas de enfermagem, Matheus e cols. (1999) chamam a atenção para a necessidade de apoio da professora, apresentada pelas alunas de enfermagem, no enfrentamento dos desafios que representam tais experiências. Esse fator é confirmado também aqui, a partir do registro da sensação de alívio explicitada pela aluna em torno da correção de um erro seu, pela professora, evitando danos ao paciente:

"Ao invés de instalar um soro glicosado a $5 \%$, instalei um ringer lactato. A professora notou e pediu que eu consertasse... O cumprimento da prescrição médica de forma correta acarretou alívio por ter corrigido o erro, antes que acontecesse algum problema ou efeitos colaterais e acarretasse danos ao paciente". (Ficha 16)

Tanto quanto o professor, os funcionários desempenham um importante papel na formação do aluno:

"Na troca de soro, ao invés de preparar um ringer simples preparei um soro glicosado, a enfermeira responsável corrigiu a tempo." (Ficha 22)

O saber-fazer no aprendizado prático da profissão, além de ser um desafio, como foi dito acima, é apresentado pelos alunos do curso técnico em enfermagem como gerador de insegurança, poucas oportunidades para realização de procedimentos mais complexos e dificuldades em lidar com as diferenças entre a técnica aprendida na escola para realização de determinados procedimentos e a técnica utilizada por alguns funcionários, ocasionando conflitos nas decisões referentes à sua atuação, como mostram as falas a seguir:

"Eu acredito que a minha maior dificuldade foi a falta de confiança e a improvisação necessária para tentar realizar um trabalho de qualidade, pois a realidade do PS está bem longe do ideal teórico que nós estudamos (exemplo: não há expurgo e no posto de enfermagem não há local ideal para o manuseio de medicação)". (Ficha I)

"Por ficarmos nos setores com um auxiliar ou técnico às vezes eles ensinam procedimentos errados e nós alunos fazemos errado só para não dizer a eles que o que fizeram estava errado". (Ficha 20)

"Na medicação: contradição em relação à diluição de remédios. A solução seria fazer do jeito que o funcionário do setor faz ou consultar e ter respaldo para fazer a medicação de forma diferente... Explicar com fatos e provar que o novo método é mais eficaz e benéfico para o bem estar do paciente. Sentimento: realização, impedir que um paciente sofresse desnecessariamente." (Ficha 32)

A forte influência da prática cotidiana sobre o saber adquirido na área de saúde, constatado neste estudo, é também relatado por Stutz (1999), ao analisar discursos de técnicos em enfermagem atuantes no mercado de trabalho que, assim como os alunos pesquisados, vêem-se também em conflito provocado pela dicotomia entre o saber e o fazer e a necessidade em aprender a lidar com o improviso. Se por um lado o aluno sente-se pressionado e confuso no ambiente de trabalho, diante da forma como determinados funcionários realizam os procedimentos durante os cuidados em enfermagem, estes, por sua vez, não raro, são forçados a improvisar, diante da falta ou escassez de material. Portanto, a dicotomia entre o saber e o fazer é fonte de conflito tanto para alunos do curso técnico de enfermagem quanto para profissionais atuantes na área, cujas causas ultrapassam a esfera individual. 


\section{Considerações finais}

Percebe-se, a partir da análise dos discursos obtidos, que o processo de aprendizagem pelo qual passam os alunos de um curso técnico em enfermagem, durante a realização de atividades práticas no ambiente de trabalho, é permeado pela forte influência das relações humanas então vivenciadas, ocupando lugar de destaque no processo de comunicação entre discentes e a equipe de funcionários junto aos quais atuam. Por esse prisma, o ambiente de aprendizagem mobiliza no aluno sentimentos de medo e ansiedade, gerando desconforto psíquico na maioria das vezes difícil de lidar. Fica evidente a forte influência dessas relações interpessoais sobre o saber-fazer, a motivação, a autoconfiança e a auto-estima do aluno. A participação efetiva, tanto dos professores quanto dos funcionários no acompanhamento do aluno, tem importante papel na redução da ansiedade, fortalecimento da autoconfiança e auto-estima do mesmo ao enfrentar os desafios que representam a aprendizagem prática da enfermagem nos contatos iniciais com o mundo do trabalho. Torna-se fundamental, portanto, reconhecer as limitações do aluno enquanto aquele que, na condição de aprendiz, está em processo de formação e estruturação de seu papel como profissional, passível por isso de erros, inseguranças e temores, os quais influenciam suas escolhas no que diz respeito à adequação das decisões a serem tomadas durante a realização do estágio.

Apesar das dificuldades enfrentadas pelo setor de saúde no país, que como se sabe geram condições desfavoráveis para um desempenho de qualidade dos funcionários e para as relações saudáveis no ambiente de trabalho, ocasionando sérios prejuízos quanto ao bem-estar e crescimento do indivíduo como um todo, faz-se necessário proporcionar aos alunos ingressantes no campo de estágio um ambiente acolhedor, no real sentido da palavra, no qual possam esclarecer suas dúvidas sem receio, serem orientados adequadamente quanto a seus erros, evitando constrangimentos de qualquer espécie e, sobretudo, que sejam estimulados a integrarem-se de fato à equipe de trabalho para que, a partir de uma atmosfera propícia para o esclarecimento de suas dúvidas e elaboração de suas vivências, possam desenvolver habilidades para resolução dos problemas enfrentados no processo de aprendizagem. Se é difícil para um funcionário experiente lidar com a complexidade característica do ambiente de trabalho, para o aluno recém-chegado é, sem dúvida, uma árdua tarefa.

Outro aspecto percebido diz respeito à necessidade de possibilitar ao aluno, sempre que possível, a execução de atividades diversificadas para que possa desenvolver o saber e o fazer de modo equilibrado, estimulando sua participação para além das tarefas rotineiras e repetitivas.

A formação de vínculos saudáveis no âmbito das relações interpessoais, sem dúvida alguma, contribui para a diminuição do estresse ocasionado pelas novas experiências, controle da ansiedade diante das dificuldades apresentadas e para a construção da identidade profissional a fim de que o aluno reconheçase como parte do grupo existente e não alguém à margem dele.

\section{Referências}

Backes, D. S., Lunardi, V. L. \& Lunardi Filho, W. D. (2006). A humanização hospitalar como expressão da ética. Revista Latino-Americana de Enfermagem, I 4 (I), I32-135.

Bardin, L. (1995). Análise de conteúdo. Lisboa: Edições 70.

Brasil. (2000). Ministério da Educação. Referenciais Curriculares Nacionais da Educação Profissional de Nível Técnico. Brasília, DF.

Davis, K. \& Newstrom, J. W. (2004a). Comportamento humano no trabalho: uma abordagem organizacional. v.2, São Paulo: Pioneira.

Davis, K. \& Newstrom, J. W. (2004b). Comportamento humano no trabalho: uma abordagem psicológica. v.I, São Paulo: Pioneira.

Fagundes, N. C. \& Burnham, T. F. (2004). Discutindo a relação entre espaço e aprendizagem na formação de profissionais de saúde. Interface-Comunicação, Saúde, Educação, 9 (6), 105-II4. 
Laudares, J. B. \& Tomasi, A. (2003). O técnico de escolaridade média no setor produtivo: seu novo lugar e suas competências. Educação e Sociedade, 24 (85), 1237-I 256.

Knapp, P., Rohde, L. A., Lyszkowski, L. \& Johannpetter, J. (2002) Terapia Cognitivo-Comportamental no Transtorno de Déficit de Atenção/Hiperatividade. Manual do Paciente. Porto Alegre: Artmed.

Kaplan, H. I., Sadock B. \& Greeb J. (1997) Compêndio de Psiquiatria: Ciências do Comportamento e Psiquiatria Clínica. ( $7^{\mathrm{a}}$ ed.). Porto Alegre: Artes Médicas.

Kobayashi, R. M. \& Leite, M. M. J. (2002). Dificuldades no estágio de administração em enfermagem sob a ótica dos alunos de nível técnico. Nursing, 5 (50), 29-34.

Lopes, A. C. (2002). Os Parâmetros Curriculares Nacionais para o Ensino Médio e a submissão ao mundo produtivo: o caso do conceito de contextualização. Educação \& Sociedade, 23 (80), 386-400.

Maluf, S. D. (1998). Ensinar ou Encenar? Uma proposta metodológica para o ensino profissionalizante. Maceió: EDUFAL

Martins, M. C. F. N. (2003). Cuidando do futuro cuidador. Em M. A. de Marco (Org.), A face humana da medicina: Do modelo biomédico ao modelo biopsicossocial (pp.87-92). São Paulo: Casa do Psicólogo.

Matheus, M. C. C., Chaves, E. C. \& Bianchi, E. R. F. (1999). A relação professora-aluna e os mecanismos de stress coping e burnout nas primeiras experiências práticas. Acta Paul. Enf. I2(3), 5I-58.

Oliveira, M. R. N. S. (2000). Mudanças no mundo do trabalho: acertos e desacertos na proposta curricular para o Ensino Médio (Resolução CNE 03/98). Diferenças entre formação técnica e formação tecnológica. Educação \& Sociedade, XXI, (70), 40-62.

Pereira, A. L. de F. (2003). As tendências pedagógicas e a prática educativa nas ciências da saúde. Cadernos de Saúde Pública, 19 (5), I527-I534.

Pezzato, L. M. (200I). O processo de formação do Técnico em Higiene Dental e do Atendente de Consultório Dentário, no Brasil: uma história silenciada. Dissertação de Mestrado Faculdade de Educação, Universidade Estadual de Campinas, Campinas.

Ramos, M. N. (2002). A educação profissional pela pedagogia das competências e superfície dos documentos oficiais. Educação e Sociedade, 23 (80), 40 I-422.

Ramos-de-Oliveira, N. (200I). Do ato de ensinar numa sociedade administrada. Cadernos Cedes, XXI (54), I927.

Renon, M. A. e Saad-Neto, M. (200I). Cirurgião-dentista: como lidar com o medo e a ansiedade de seu paciente. Revista Regional de Araçatuba A.P.C.D., 22 (I),05-08.

Silva, M. V. (200I). Empresa e Escola: do discurso da sedução a uma relação complexa. Tese de Doutorado - Faculdade de Educação, Universidade Estadual de Campinas, Campinas, SP.

Stutz, B. L. (1999). Técnico de Enfermagem: o perfil traçado por profissionais da área. Revista Brasileira de Enfermagem, $52(4), 606-6 \mid 4$

Recebido em: 10/08/2006

Revisado em: 08/12/2006

Aprovado em: 18/12/2006

Sobre as autoras

Beatriz Lemos Stutz (beatriz.stutz@netsite.com.br) é psicóloga, mestre em Educação, docente da Escola Técnica de Saúde da Universidade Federal de Uberlândia, Minas Gerais.

Adriane Corrêa Jansen (dijansen@centershop.com.br) é enfermeira, mestre em Enfermagem, docente da Escola Técnica de Saúde da Universidade Federal de Uberlândia, Minas Gerais.

Endereços para correspondência

Beatriz Lemos Stutz

Escola Técnica de Saúde - UFU. Av. Amazonas s/n Bloco 4K, sala 25. Campus Umuarama

38400-902 - Uberlândia, MG. 